\title{
Kuznets Curves Stratified by Mean per Capita Income, 1969-2007: Implications Regarding Global Economic Development and Income Inequality ${ }^{*}$
}

\author{
Jack E. Riggs ${ }^{1}$, Jeffrey C. Hobbs ${ }^{2}$, Gerald R. Hobbs ${ }^{3}$, Todd H. Riggs ${ }^{4}$ \\ ${ }^{1}$ Department of Neurology, West Virginia University, Morgantown, USA \\ ${ }^{2}$ Department of Finance, Banking and Insurance, Appalachian State University, Boone, USA \\ ${ }^{3}$ Department of Statistics, West Virginia University, Morgantown, USA \\ ${ }^{4}$ 159th Aviation Brigade, United States Army, Fort Campbell, USA \\ Email: jriggs@wvu.edu, hobbsjc@appstate.edu, ghobbs@stat.wvu.edu, todd.riggs@us.army.mil
}

Received June 6, 2012; revised July 5, 2012; accepted July 14, 2012

\begin{abstract}
A Kuznets curve, based upon GDP and population estimates for the years 1969 through 2007 from 36 nations and regions comprising the entire global economy and population, has been previously demonstrated. This global Kuznets curve of income inequality was a mathematical consequence of the definition of income inequality used (the coefficient of variation, which is the standard deviation divided by the mean) and two observations; the standard deviation of population-weighted national/regional mean per capita income increased linearly, and the mean global per capita income increased exponentially over the period investigated. In this analysis, these same 36 nations/regions were stratified into three groups based upon their 1969 mean per capita income to determine if those observations were also applicable to this subgroup analysis. This study demonstrated that between 1969 and 2007, population-weighed income inequality actually increased in the two richest groups and decreased in the poorest group. This observation was primarily produced by the finding that the exponential rate of growth of the population-weighted mean per capita income in the poorest group was nearly twice that of the two richest groups. This finding suggests that Kuznets hypothesis that increasing income inequality was an early feature of economic development and that decreasing income inequality was a late feature of economic development is not applicable to a global economy stratified on the basis of mean per capita income.
\end{abstract}

Keywords: Economic Development; Global Economy; Income Inequality; Kuznets Curve

\section{Introduction}

Kuznets [1] hypothesized that national economic development was associated initially with increasing income inequality followed by decreasing income inequality, which describes the distinctive inverted U shape Kuznets curve. Kuznets [1] postulated that this relationship between economic development and income inequality was produced by the combined effects of urbanization and industrialization and was associated with the movement of labor from lower paying rural agricultural jobs to higher paying urban industrial jobs. Kuznets curves have only been variably found within nations and regions [2-6]. However, the vast majority of the world's income inequality is betweennation and not within-nation $[7,8]$. Using population and GDP data from 1969 through 2007 from 36 nations and regions that comprised the entire global economy, a global

${ }^{*}$ The opinions and assertions herein are those of the authors and do not necessarily reflect those of the United States Army.
Kuznets curve was previously demonstrated [9]. Furthermore, it was suggested that this global Kuznets curve of income inequality was actually a mathematical consequence of the definition of income inequality used (the coefficient of variation) and two observations; the standard deviation of population-weighted national/regional mean per capita income was increasing linearly, and the mean global per capita income was increasing exponentially [9]. In this study, we sought to determine whether those observations regarding the production of the global Kuznets curve would also exist if the global economy were stratified on the basis of mean per capita income.

\section{Data and Methods}

National and regional population and gross domestic product (GDP) estimates (in dollars adjusted to the year 2000) from 1969 through 2007 were obtained from the Economic Research Service of the United States Department of Agriculture (www.ers.usda.gov). This data set represented the 
longest period of time and included the best estimates of the total world economy and population that we could find. The data set was consolidated into 36 nations and regions as displayed in Table 1 (Canada, United States, Mexico, Caribbean and Central America, Argentina, Brazil, Other South America, European Union 15, European Union New 10, Other Western Europe, Other Central Europe, Russia, Ukraine, Other Former Soviet Union, China, Hong Kong, Japan, South Korea, Taiwan, Other East Asia, Southeast Asia, Bangladesh, India, Pakistan, Other South Asia, Australia, New Zealand, Other Oceania, Iran, Iraq, Saudi Arabia, Turkey, Other Middle East, North Africa, Republic of South Africa, and Other Subsahara) over this time period such that the sum of their individual population and GDP estimates were equal to the total world population and GDP estimates. Annual per capita GDP (in year 2000 dollars) was calculated for each of these 36 nations and regions and for the world for the years 1969 through 2007.

These 36 nations and regions were then stratified into three groups (12 in each group) based upon their 1969 annual per capita GDP (in year 2000 dollars). These three groups were designated Top, Middle, and Bottom groups. The 12 nations and regions included in each group are shown in Table 1. Only four nations/regions actually changed groups between 1969 and 2007. Mexico and Other Middle East moved from the TOP group to the MIDDLE group. South Korea and Taiwan moved from the MIDDLE group to the TOP group. However, for the purpose of this analysis, all nations and regions were left in the group originally assigned based upon their 1969 annual per capita GDP (in year 2000 dollars).

Table 1. The 36 nations/regions comprising the total world population and total world GDP were stratified into three groups based upon their mean per capita GDP in 1969. The 12 nations/regions with the highest mean per capita GDP in 1969 were grouped in the TOP. The 12 nations/regions with the lowest mean per capita GDP in 1969 were grouped in the BOTTOM. The remaining 12 nations/regions were grouped in the MIDDLE. The nations/regions are listed alphabetically.

\begin{tabular}{ccc}
\hline TOP & MIDDLE & BOTTOM \\
\hline Argentina & Brazil & Bangladesh \\
Australia & Caribbean and Central & China \\
Canada & Emerica & India \\
European Union 15 & Iran & Iraq \\
Hong Kong & Other Central Europe & North Africa \\
Japan & Other Oceania & Other East Europe \\
Mexico & Other South America & Other Former Soviet \\
New Zealand & Republic of South & Other South Asia \\
Other Middle East & Africa & Other Subsahara \\
Other Western Europe & Russia & Pakistan \\
Saudi Arabia & South Korea & Southeast Asia \\
United States & Taiwan & Ukraine \\
\hline
\end{tabular}

Table 2 summarizes the changes in WORLD population and GDP between 1969 and 2007 and also illustrates the magnitude and proportional changes seen in population and GDP in the TOP, MIDDLE, and BOTTOM groups between 1969 and 2007. Table 2 also summarizes changes in the WORLD, TOP, MIDDLE, and BOTTOM groups in their mean per capita GDP between 1969 and 2007.

\section{Results}

\subsection{Top}

The mean per capita GDP (Mean pcGDP) (in year 2000 dollars) for the TOP group for the years 1969 through 2007 is shown in Table 3. The logarithm (base 10) of the TOP group annual mean per capita GDP [LOG (Mean pcGDP)] is also shown in Table 3. The standard deviation of the population-weighted per capita GDP (SD pcGDP) of the 12 nations and regions in the TOP group analyzed in this study for the years 1969 through 2007 is also shown in Table 3. The coefficient of variation (defined as the standard deviation divided by the mean) is a commonly used measure of inequality. The population-weighted percent coefficient of variation (Percent CV) of per capita GDP for the TOP group was calculated and is shown in Table 3.

Figure 1 shows the population-weighted percent coefficient of variation of per capita GDP of the TOP group plotted against year. This plot illustrates that income inequality increased in the TOP group. Figure 2 shows the plot of the standard deviation of the population-weighted per capita GDP (in year 2000 dollars) for the TOP group for the years 1969 through 2007. As seen, this standard deviation increases in a nearly linear fashion over time. Linear regression analysis of the data displayed in Figure 2 yielded the following equation:

$$
\text { SD pcGDP }(\text { TOP })=217.52(\text { YR })-424119.1
$$

where SD pcGDP (TOP) is the standard deviation of the population-weighted per capita GDP (in year 2000 dollars) of the TOP group and YR is the year. The $\mathrm{R}^{2}$ value of the linear fit of the data displayed in Figure $\mathbf{2}$ is greater than 0.988. Figure 3 shows the plot of the logarithm of the mean per capita GDP (in year 2000 dollars) of the TOP group for the years 1969 through 2007. As seen, the logarithm of the annual mean TOP group per capita GDP also increases in a nearly linear fashion over time. Linear regression analysis of the data displayed in Figure 3 yielded the following equation:

$$
\begin{aligned}
\operatorname{LOG}(\text { Mean TOP pcGDP })= & 0.018234(\mathrm{YR}) \\
& -26.40732
\end{aligned}
$$

where LOG (Mean TOP pcGDP) is the logarithm of the mean TOP group per capita GDP (in year 2000 dollars) and $\mathrm{YR}$ is the year. The $\mathrm{R}^{2}$ value of the linear fit of the data 
Table 2. The WORLD, TOP, MIDDLE, and BOTTOM population and GDP (expressed in billions of year 2000 dollars) for the years 1969 and 2007 are shown. The numbers in parentheses are the percent of the WORLD population and GDP that the groups TOP, MIDDLE, and BOTTOM account for in the years 1969 and 2007. The mean per capita GDP (in year 2000 dollars) for the WORLD and groups TOP, MIDDLE, and BOTTOM are also shown for the years 1969 and 2007.

\begin{tabular}{ccccc}
\hline & WORLD & TOP & MIDDLE & BOTTOM \\
\cline { 2 - 5 } POPULATION & & & & \\
1969 & $3,632,821,593$ & $798,668,544(22.0)$ & $583,870,671(16.1)$ & $2.250,282,378(61.9)$ \\
2007 & $6,605,046,992$ & $1,139,113,291(17.2)$ & $954,567,178(14.5)$ & $4,511,366,523(68.2)$ \\
GDP & & & & \\
1969 & 11829.75 & $10166.85(85.9)$ & $1077.37(9.1)$ & $585.53(4.9)$ \\
2007 & 39109.85 & $30078.28(76.9)$ & $4152.81(10.6)$ & $4878.75(12.5)$ \\
MEAN PER CAPITA GDP & & & & \\
1969 & 3256.35 & 12729.75 & 1845.21 & 260.20 \\
2007 & 5921.21 & 26405.00 & 4350.47 & 1081.44 \\
\hline
\end{tabular}

Table 3. Mean and logarithm (LOG) of mean per capita (pc) GDP, standard deviation (SD) of pcGDP, and population-weighted percent coefficient of variation (CV) for the 12 nations/regions comprising the TOP group of mean pcGDP's in 1969 for the years 1969 through 2007.

\begin{tabular}{|c|c|c|c|c|}
\hline Year & Mean pcGDP & LOG (Mean pcGDP) & SD pcGDP & Percent CV \\
\hline 1969 & 1845.21 & 3.266 & 391.47 & 21.22 \\
\hline 1970 & 1903.93 & 3.280 & 401.04 & 21.06 \\
\hline 1971 & 1967.78 & 3.309 & 402.49 & 20.45 \\
\hline 1972 & 2037.90 & 3.329 & 406.15 & 19.93 \\
\hline 1973 & 2130.86 & 3.342 & 444.99 & 20.88 \\
\hline 1974 & 2195.91 & 3.342 & 469.85 & 21.40 \\
\hline 1975 & 2237.29 & 3.350 & 473.11 & 21.15 \\
\hline 1976 & 2336.27 & 3.369 & 479.10 & 20.51 \\
\hline 1977 & 2414.06 & 3.383 & 513.89 & 21.29 \\
\hline 1978 & 2458.18 & 3.391 & 556.51 & 22.64 \\
\hline 1979 & 2514.08 & 3.400 & 616.63 & 24.53 \\
\hline 1980 & 2548.59 & 3.406 & 678.25 & 26.61 \\
\hline 1981 & 2543.32 & 3.405 & 685.31 & 26.95 \\
\hline 1982 & 2550.62 & 3.407 & 682.07 & 26.74 \\
\hline 1983 & 2548.78 & 3.406 & 709.26 & 27.83 \\
\hline 1984 & 2623.46 & 3.419 & 780.62 & 29.76 \\
\hline 1985 & 2680.90 & 3.428 & 832.63 & 31.06 \\
\hline 1986 & 2778.17 & 3.444 & 954.47 & 34.36 \\
\hline 1987 & 2865.93 & 3.457 & 1079.76 & 37.68 \\
\hline 1988 & 2912.33 & 3.464 & 1191.18 & 40.90 \\
\hline 1989 & 2949.57 & 3.470 & 1288.16 & 43.67 \\
\hline 1990 & 2945.10 & 3.469 & 1384.11 & 47.00 \\
\hline 1991 & 2929.79 & 3.467 & 1503.35 & 51.31 \\
\hline 1992 & 2888.72 & 3.461 & 1621.72 & 56.14 \\
\hline 1993 & 2931.07 & 3.467 & 1735.80 & 59.22 \\
\hline 1994 & 2971.58 & 3.473 & 1904.30 & 64.08 \\
\hline 1995 & 3086.64 & 3.489 & 2065.13 & 66.91 \\
\hline 1996 & 3172.17 & 3.501 & 2202.19 & 69.42 \\
\hline 1997 & 3276.48 & 3.515 & 2310.33 & 70.51 \\
\hline 1998 & 3248.37 & 3.512 & 2249.84 & 69.26 \\
\hline 1999 & 3305.37 & 3.519 & 2414.02 & 73.03 \\
\hline 2000 & 3457.47 & 3.539 & 2569.10 & 74.31 \\
\hline 2001 & 3489.63 & 3.543 & 2570.04 & 73.65 \\
\hline 2002 & 3589.89 & 3.555 & 2703.58 & 75.31 \\
\hline 2003 & 3675.50 & 3.565 & 2768.65 & 75.33 \\
\hline 2004 & 3860.72 & 3.587 & 2877.33 & 74.53 \\
\hline 2005 & 4014.34 & 3.604 & 2985.38 & 74.37 \\
\hline 2006 & 4186.26 & 3.622 & 3133.90 & 74.86 \\
\hline 2007 & 4350.47 & 3.639 & 3267.12 & 75.10 \\
\hline
\end{tabular}


displayed in Figure 3 is greater than 0.991.

\subsection{Middle}

The mean per capita GDP (Mean pcGDP) (in year 2000 dollars) for the MIDDLE group for the years 1969 through 2007 is shown in Table 4. The logarithm (base 10) of the

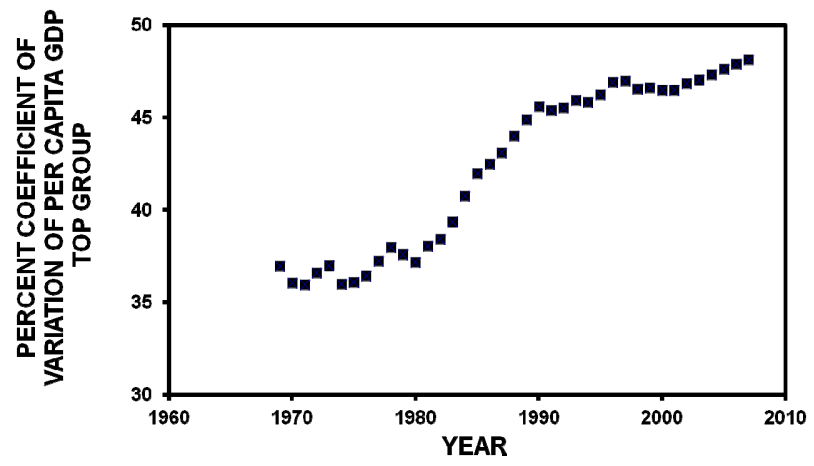

Figure 1. Annual population-weighted coefficient of variation of per capital GDP (in year 2000 dollars) for the 12 nations/regions comprising the TOP group for the years 1969 through 2007.

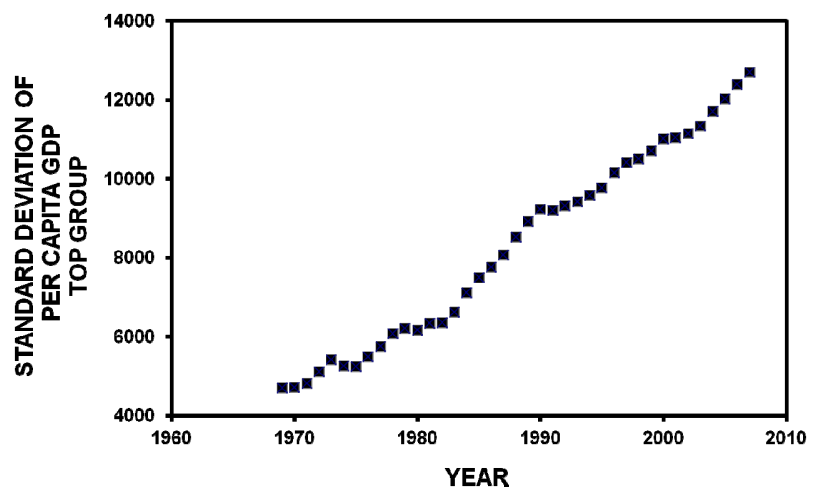

Figure 2. Annual standard deviation of per capital GDP (in year 2000 dollars) for the 12 nations/regions comprising the TOP group for the years 1969 through 2007.

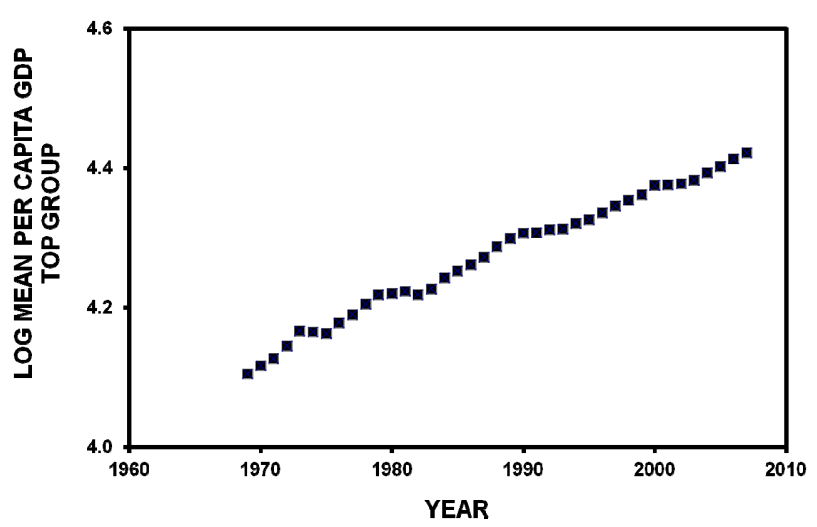

Figure 3. Logarithm (LOG) of annual mean per capital GDP (in year 2000 dollars) for the 12 nations/regions comprising the TOP group for the years 1969 through 2007.
MIDDLE group annual mean per capita GDP [LOG (Mean pcGDP)] is also shown in Table 4. The standard deviation of the population-weighted per capita GDP (SD pcGDP) of the 12 nations and regions in the MIDDLE group analyzed in this study for the years 1969 through 2007 is also shown in Table 4. The population-weighted percent coefficient of variation (Percent CV) of per capita GDP for the MIDDLE group was calculated and is shown in Table 4.

Figure 4 shows the population-weighted percent coefficient of variation of per capita GDP of the MIDDLE group plotted against year. This plot illustrates that income inequality also increased in the MIDDLE group. Figure 5 shows the plot of the standard deviation of the population-weighted per capita GDP (in year 2000 dollars) for the MIDDLE group for the years 1969 through 2007. As seen, this standard deviation increases in a somewhat linear fashion over time. This linear increase actually appears to have increased after the early 1980's. Nevertheless, linear regression analysis of the data displayed in Figure 5 yielded the following equation:

$$
\text { SD pcGDP }(\text { MIDDLE })=80.89(\text { YR })-159,360
$$

where SD pcGDP (MIDDLE) is the standard deviation of the population-weighted per capita GDP (in year 2000 dollars) of the MIDDLE group and YR is the year. The $\mathrm{R}^{2}$ value of the linear fit of the data displayed in Figure $\mathbf{5}$ is greater than 0.945. Figure 6 shows the plot of the logarithm of the mean per capita GDP (in year 2000 dollars) of the MIDDLE group for the years 1969 through 2007. As seen, the logarithm of the annual mean MIDDLE group per capita GDP also increases in a nearly linear fashion over time. Linear regression analysis of the data displayed in Figure 6 yielded the following equation:

$$
\begin{aligned}
\text { LOG }(\text { Mean MIDDLE pcGDP })= & 0.0187266(\text { YR }) \\
& -29.28487
\end{aligned}
$$

where LOG (Mean MIDDLE pcGDP) is the logarithm of the mean MIDDLE group per capita GDP (in year 2000

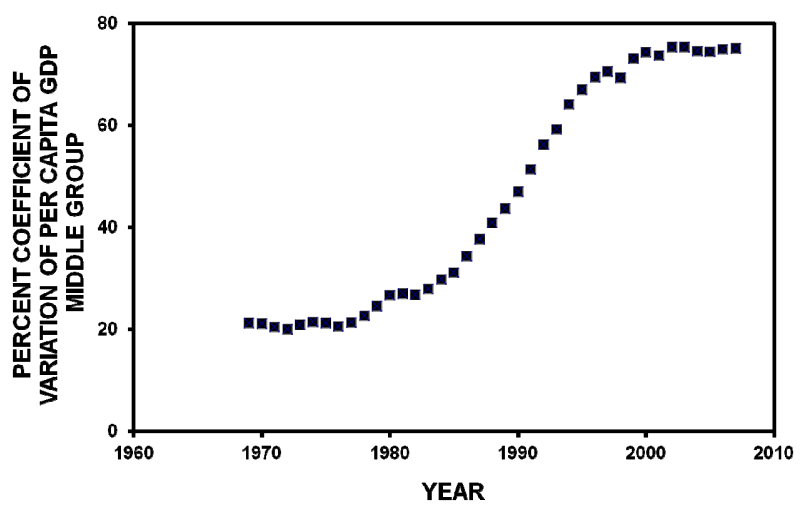

Figure 4. Annual population-weighted coefficient of variation of per capital GDP (in year 2000 dollars) for the 12 nations/regions comprising the MIDDLE group for the years 1969 through 2007. 
dollars) and YR is the year. The $\mathrm{R}^{2}$ value of the linear fit of the data displayed in Figure 6 is greater than 0.968.

\subsection{Bottom}

The mean per capita GDP (Mean pcGDP) (in year 2000 dollars) for the BOTTOM group for the years 1969 through 2007 is shown in Table 5. The logarithm (base 10) of the BOTTOM group annual mean per capita GDP [LOG
(Mean pcGDP)] is also shown in Table 5. The standard deviation of the population-weighted per capita GDP (SD pcGDP) of the 12 nations and regions in the BOTTOM group analyzed in this study for the years 1969 through 2007 is also shown in Table 5. The population-weighted percent coefficient of variation (Percent CV) of per capita GDP for the BOTTOM group was calculated and is shown in Table 5.

Table 4. Mean and logarithm (LOG) of mean per capita (pc) GDP, standard deviation (SD) of pcGDP, and population-weighted percent coefficient of variation (CV) for the 12 nations/regions comprising the MIDDLE group of mean pcGDP's in 1969 for the years 1969 through 2007.

\begin{tabular}{|c|c|c|c|c|}
\hline Year & Mean pcGDP & LOG (Mean pcGDP) & SD pcGDP & Percent CV \\
\hline 1969 & 1845.21 & 3.266 & 391.47 & 21.22 \\
\hline 1970 & 1903.93 & 3.280 & 401.04 & 21.06 \\
\hline 1971 & 1967.78 & 3.309 & 402.49 & 20.45 \\
\hline 1972 & 2037.90 & 3.329 & 406.15 & 19.93 \\
\hline 1973 & 2130.86 & 3.342 & 444.99 & 20.88 \\
\hline 1974 & 2195.91 & 3.342 & 469.85 & 21.40 \\
\hline 1975 & 2237.29 & 3.350 & 473.11 & 21.15 \\
\hline 1976 & 2336.27 & 3.369 & 479.10 & 20.51 \\
\hline 1977 & 2414.06 & 3.383 & 513.89 & 21.29 \\
\hline 1978 & 2458.18 & 3.391 & 556.51 & 22.64 \\
\hline 1979 & 2514.08 & 3.400 & 616.63 & 24.53 \\
\hline 1980 & 2548.59 & 3.406 & 678.25 & 26.61 \\
\hline 1981 & 2543.32 & 3.405 & 685.31 & 26.95 \\
\hline 1982 & 2550.62 & 3.407 & 682.07 & 26.74 \\
\hline 1983 & 2548.78 & 3.406 & 709.26 & 27.83 \\
\hline 1984 & 2623.46 & 3.419 & 780.62 & 29.76 \\
\hline 1985 & 2680.90 & 3.428 & 832.63 & 31.06 \\
\hline 1986 & 2778.17 & 3.444 & 954.47 & 34.36 \\
\hline 1987 & 2865.93 & 3.457 & 1079.76 & 37.68 \\
\hline 1988 & 2912.33 & 3.464 & 1191.18 & 40.90 \\
\hline 1989 & 2949.57 & 3.470 & 1288.16 & 43.67 \\
\hline 1990 & 2945.10 & 3.469 & 1384.11 & 47.00 \\
\hline 1991 & 2929.79 & 3.467 & 1503.35 & 51.31 \\
\hline 1992 & 2888.72 & 3.461 & 1621.72 & 56.14 \\
\hline 1993 & 2931.07 & 3.467 & 1735.80 & 59.22 \\
\hline 1994 & 2971.58 & 3.473 & 1904.30 & 64.08 \\
\hline 1995 & 3086.64 & 3.489 & 2065.13 & 66.91 \\
\hline 1996 & 3172.17 & 3.501 & 2202.19 & 69.42 \\
\hline 1997 & 3276.48 & 3.515 & 2310.33 & 70.51 \\
\hline 1998 & 3248.37 & 3.512 & 2249.84 & 69.26 \\
\hline 1999 & 3305.37 & 3.519 & 2414.02 & 73.03 \\
\hline 2000 & 3457.47 & 3.539 & 2569.10 & 74.31 \\
\hline 2001 & 3489.63 & 3.543 & 2570.04 & 73.65 \\
\hline 2002 & 3589.89 & 3.555 & 2703.58 & 75.31 \\
\hline 2003 & 3675.50 & 3.565 & 2768.65 & 75.33 \\
\hline 2004 & 3860.72 & 3.587 & 2877.33 & 74.53 \\
\hline 2005 & 4014.34 & 3.604 & 2985.38 & 74.37 \\
\hline 2006 & 4186.26 & 3.622 & 3133.90 & 74.86 \\
\hline 2007 & 4350.47 & 3.639 & 3267.12 & 75.10 \\
\hline
\end{tabular}




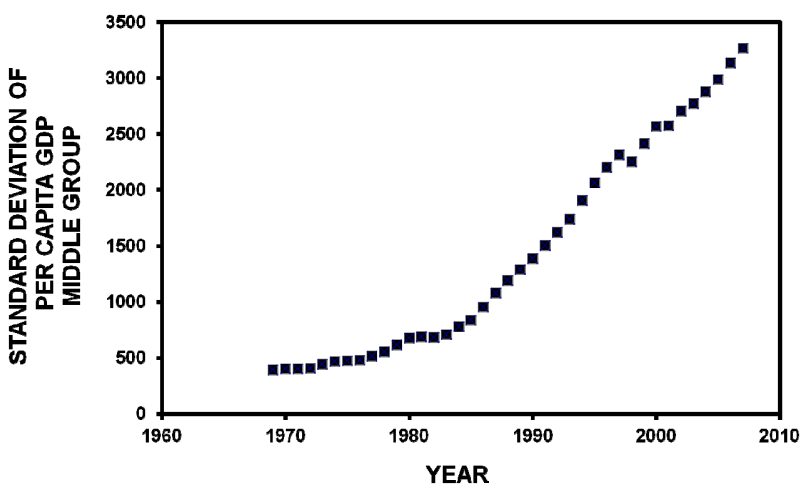

Figure 5. Annual standard deviation of per capital GDP (in year 2000 dollars) for the 12 nations/regions comprising the MIDDLE group for the years 1969 through 2007.

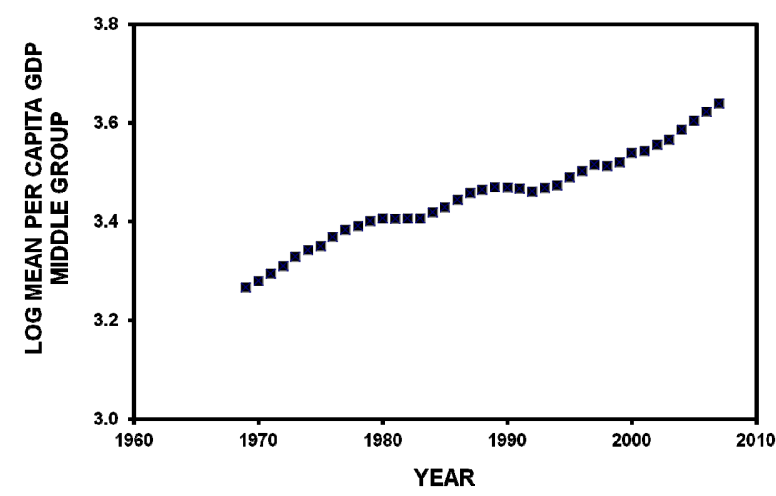

Figure 6. Logarithm (LOG) of annual mean per capital GDP (in year 2000 dollars) for the 12 nations/regions comprising the MIDDLE group for the years 1969 through 2007.

Table 5. Mean and logarithm (LOG) of mean per capita (pc) GDP, standard deviation (SD) of pcGDP, and population-weighted percent coefficient of variation (CV) for the 12 nations/regions comprising the BOTTOM group of mean pcGDP's in 1969 for the years 1969 through 2007.

\begin{tabular}{|c|c|c|c|c|}
\hline Year & Mean pcGDP & LOG (Mean pcGDP) & SD pcGDP & Percent CV \\
\hline 1969 & 260.20 & 2.415 & 213.52 & 82.06 \\
\hline 1970 & 273.95 & 2.438 & 215.74 & 78.75 \\
\hline 1971 & 277.04 & 2.443 & 213.71 & 77.14 \\
\hline 1972 & 278.84 & 2.445 & 220.66 & 79.14 \\
\hline 1973 & 286.61 & 2.457 & 222.59 & 77.66 \\
\hline 1974 & 291.15 & 2.464 & 226.80 & 77.90 \\
\hline 1975 & 300.20 & 2.477 & 230.63 & 76.83 \\
\hline 1976 & 307.82 & 2.488 & 247.65 & 80.45 \\
\hline 1977 & 319.74 & 2.505 & 254.86 & 79.71 \\
\hline 1978 & 331.85 & 2.521 & 257.86 & 77.70 \\
\hline 1979 & 337.81 & 2.529 & 267.52 & 79.19 \\
\hline 1980 & 348.57 & 2.542 & 270.67 & 77.65 \\
\hline 1981 & 355.10 & 2.550 & 268.49 & 75.61 \\
\hline 1982 & 364.89 & 2.562 & 273.59 & 74.98 \\
\hline 1983 & 378.41 & 2.578 & 276.26 & 73.01 \\
\hline 1984 & 392.81 & 2.594 & 275.98 & 70.26 \\
\hline 1985 & 406.65 & 2.609 & 273.76 & 67.32 \\
\hline 1986 & 417.30 & 2.620 & 270.38 & 64.79 \\
\hline 1987 & 432.34 & 2.636 & 268.64 & 62.14 \\
\hline 1988 & 457.40 & 2.660 & 274.39 & 59.99 \\
\hline 1989 & 471.97 & 2.674 & 283.87 & 60.15 \\
\hline 1990 & 482.47 & 2.683 & 283.68 & 58.80 \\
\hline 1991 & 493.10 & 2.693 & 278.37 & 56.45 \\
\hline 1992 & 512.31 & 2.710 & 270.91 & 52.88 \\
\hline 1993 & 534.70 & 2.728 & 271.37 & 50.75 \\
\hline 1994 & 562.24 & 2.750 & 280.17 & 49.83 \\
\hline 1995 & 593.53 & 2.773 & 292.51 & 49.28 \\
\hline 1996 & 627.78 & 2.798 & 311.17 & 49.57 \\
\hline 1997 & 654.87 & 2.816 & 323.48 & 49.40 \\
\hline 1998 & 666.62 & 2.824 & 316.25 & 47.44 \\
\hline 1999 & 694.86 & 2.842 & 329.36 & 47.40 \\
\hline 2000 & 728.62 & 2.863 & 347.19 & 47.65 \\
\hline 2001 & 757.13 & 2.879 & 361.61 & 47.76 \\
\hline 2002 & 791.73 & 2.899 & 385.61 & 48.70 \\
\hline 2003 & 838.89 & 2.924 & 414.83 & 49.45 \\
\hline 2004 & 894.37 & 2.952 & 449.24 & 50.23 \\
\hline 2005 & 953.42 & 2.979 & 484.82 & 50.85 \\
\hline 2006 & 1016.11 & 3.007 & 525.76 & 51.74 \\
\hline 2007 & 1081.44 & 3.034 & 571.79 & 52.87 \\
\hline
\end{tabular}


Figure 7 shows the population-weighted percent coefficient of variation of per capita GDP of the BOTTOM group plotted against year. This plot illustrates that income inequality initially sharply decreased in the BOTTOM group, and then more recently has increased. Figure 8 shows the plot of the standard deviation of the population-weighted per capita GDP (in year 2000 dollars) for the BOTTOM group for the years 1969 through 2007. As seen, this standard deviation did not increase in a reasonably linear fashion over time. The increase actually appears to have dramatically increased after the early 1990's. Nevertheless, linear regression analysis of the data displayed in Figure 7 yielded the following equation:

$$
\begin{aligned}
\mathrm{SD} \text { pcGDP }(\mathrm{BOTTOM})= & 6.2970717(\mathrm{YR}) \\
& -12215.87
\end{aligned}
$$

where SD pcGDP (BOTTOM) is the standard deviation of the population-weighted per capita GDP (in year 2000 dollars) of the BOTTOM group and YR is the year. The $\mathrm{R}^{2}$ value of the linear fit of the data displayed in Figure 8 is greater than 0.721 . Figure 9 shows the plot of the logarithm of the mean per capita GDP (in year 2000 dollars) of the BOTTOM group for the years 1969 through 2007. As seen, the logarithm of the annual mean BOTTOM group per capita GDP also increases in a nearly linear fashion over time. Linear regression analysis of the data displayed in Figure 9 yielded the following equation:

$$
\begin{aligned}
\text { LOG }(\text { Mean BOTTOM pcGDP })= & 0.0362175(\text { YR }) \\
& -65.83887
\end{aligned}
$$

where LOG (Mean BOTTOM pcGDP) is the logarithm of the mean BOTTOM group per capita GDP (in year 2000 dollars) and YR is the year. The $\mathrm{R}^{2}$ value of the linear fit of the data displayed in Figure 9 is greater than 0.983.

\section{Conclusions}

A global Kuznets curve was demonstrated using global economic and population data for the years 1969 through 2007 [9]. That global between-nation/region Kuznets curve showed initial increasing income inequality followed by decreasing income inequality [9] as was hypothesized by Kuznets [1] and associated with global economic development. Furthermore, this distinctive inverted U shape global Kuznets curve was suggested to be a mathematical consequence of the definition of the measure of income inequality used and two observations relevant to that definition [9]. The measure of economic inequality used in that analysis was the coefficient of variation, which is defined by the equation:

$$
\mathrm{CV}=\mathrm{SD} / \mathrm{MEAN}
$$

in which CV is the coefficient of variation and SD is the standard deviation, a measure of spread. The global SD

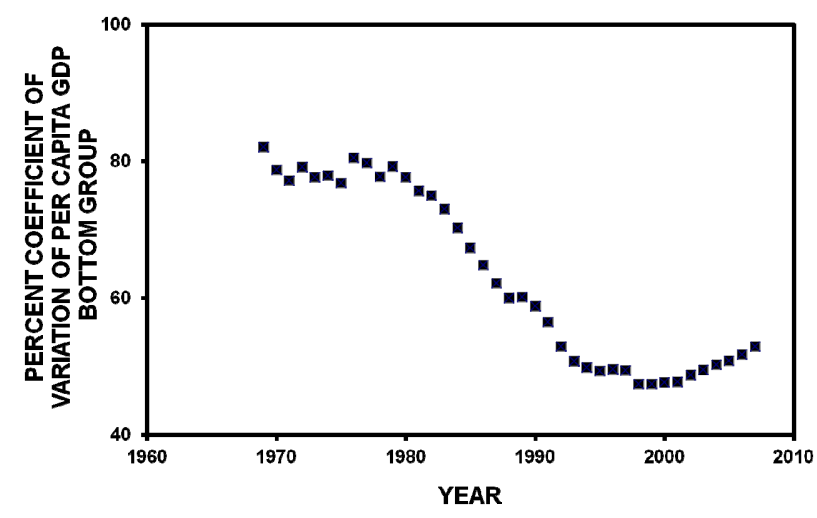

Figure 7. Annual population-weighted coefficient of variation of per capital GDP (in year 2000 dollars) for the 12 nations/regions comprising the BOTTOM group for the years 1969 through 2007.

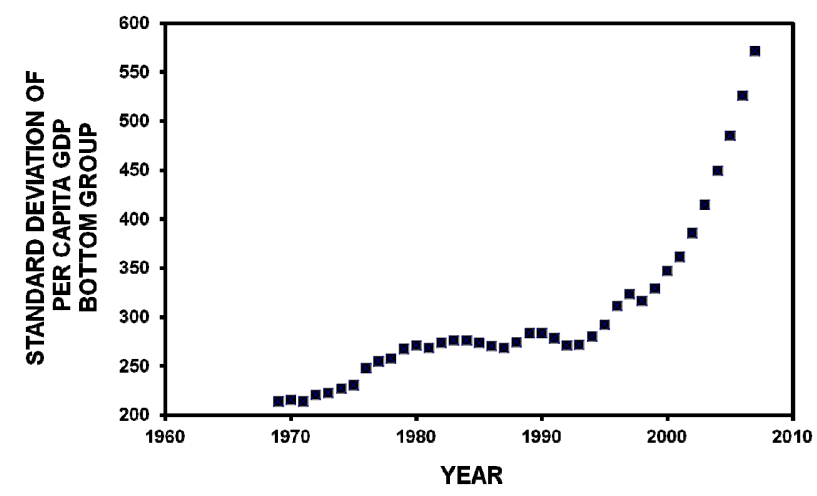

Figure 8. Annual standard deviation of per capital GDP (in year 2000 dollars) for the 12 nations/regions comprising the BOTTOM group for the years 1969 through 2007.

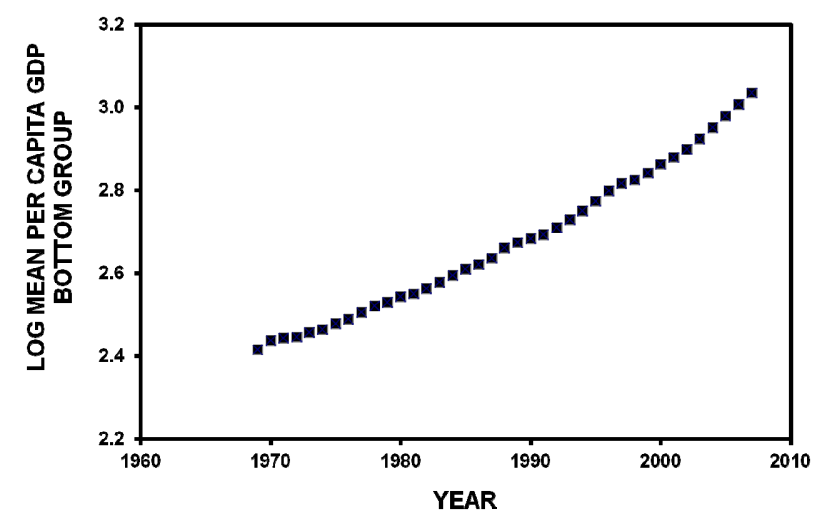

Figure 9. Logarithm (LOG) of annual mean per capital GDP (in year 2000 dollars) for the 12 nations/regions comprising the BOTTOM group for the years 1969 through 2007.

or spread of the population-weighted per capita income was noted to increase linearly between 1969 and 2007 [9], while the mean world per capita income was noted to increase exponentially between 1969 and 2007 [9]. Since the mean global per capita income was increasing exponentially, eventually the exponentially increasing denominator 
in Equation (7) will dominate the linearly increasing numerator, and the coefficient of variation, or income inequality, must eventually decrease [9]. It was also emphasized that this mathematical explanation for the global Kuznets curve was dependent not only on the initial conditions in the data, but also the period of time over which the analysis was conducted [9].

In the present analysis, the world's nations and region were stratified by mean per capita GDP to determine if the subgroup SD also increased linearly and the subgroup MEAN also increased exponentially. As Equations (2), (4), and (6) and Figures 3, 6, and 9 demonstrate, there was an exponential rate of increase in the mean per capita GDP in all three groups. Moreover, the exponential rate of increase in the mean per capita GDP in the two richest groups (TOP and MIDDLE) is about twice that of the poorest group (BOTTOM); that is 1.8234 percent and 1.87266 percent respectively compared to 3.62175 percent. Thus, ultimately the BOTTOM group should demonstrate more rapid decreasing income inequality than the TOP and MIDDLE groups, which is what was observed. Thus, contrary to what Kuznets suggested, from a global perspective, the least economically developed nations/regions experienced earlier and more rapid decreasing income inequality.

Similar to what was observed when global economies were not stratified [9], the SD of the population-weighted per capita GDP increased reasonably linearly in the TOP and MIDDLE groups as was demonstrated in Equations (1) and (3) and Figures 2 and 5. In the BOTTOM group, however, the SD of the population-weighted per capita GDP showed a much more apparent rapid rate of increase beginning in the early 1990's (Figure 8) which resulted in some increasing income inequality in the BOTTOM group after year 2000 (Figure 7).

These findings are consistent with the thesis that ultimately globalization of the world's economy will be associated with decreasing international income inequality [10]. Moreover, these findings also suggest that although much international income inequality exists, the world's poorest nations will likely demonstrate the greatest relative economic growth (Table 2), as long as those nations maintain the political and economic stability required to take advantage of the relative ease of international capital and technology flows that are necessary to utilize and take advantage of cheaper labor markets [11]. Despite its economic implications, the ultimate relative decreasing income equality of the world's population will likely have significant political implications and expectations with respect to future world political and economic development [12].

Although a global Kuznets curve, with its distinctive inverted U shape, was demonstrated for the global economy between 1969 and 2007 [9], the inverted U was not demonstrated within the world's TOP, MIDDLE, and
BOTTOM groups. Although Kuznets [1] hypothesized that national economic development was associated initially with increasing income inequality followed by decreasing income inequality, the two richest and most developed economic groups in this study actually displayed only the first half of the inverted U shape of a Kuznets curve. During the time period of this study, the most developed economies (the TOP and MIDDLE groups) actually displayed increasing income inequality, primarily reflecting their low rate of exponential growth in their mean per capita GDP (Figures 1 and 4). By comparison, the least developed economies (the BOTTOM group) displayed decreasing income inequality, primarily reflecting their much higher rate of exponential growth in their mean per capita GDP (Figure 7). Consequently, Kuznets’ postulated relationship between status of economic development and income inequality is not applicable in national/regional economies stratified by mean per capita income in the short-term. This conclusion is based upon the ability of a globalized economy, with accessible low-cost labor forces in poor countries, to more relatively rapidly increase the mean income in poor counties driving down their subgroup income inequality despite their relative poorer state of overall economic development. Nevertheless, in the long-term, Kuznets’ prediction regarding decreasing income inequality, at least from the between nation perspective in the global economy, is likely to prove accurate.

\section{REFERENCES}

[1] S. Kuznets, "Economic Growth and Income Inequality," American Economic Review, Vol. 45, No. 1, 1955, pp. 128.

[2] S. Robinson, "A Note on the U Hypothesis Relating Income Inequality and Economic Development," American Economic Review, Vol. 66, No. 3, 1976, pp. 437-440.

[3] M. Braulke, “A Note on Kuznets' U,” Review of Economics and Statistics, Vol. 65, No. 1, 1983, pp. 135-139. doi: $10.2307 / 1924418$

[4] R. Ram, “Kuznets's Inverted-U Hypothesis: Evidence from a Highly Developed Country," Southern Economic Journal, Vol. 57, No. 4, 1991, pp. 1112-1123. doi: $10.2307 / 1060338$

[5] O. Galor and D. Tsiddon, "Income Distribution and Growth: The Kuznets Hypothesis Revisited,” Economica, Vol. 63, No. 250, 1996, pp. S103-S117. doi:10.2307/2554811

[6] T. P. Moran, “Kuznets’s Inverted U-Curve Hypothesis: the Rise, Demise, and Continued Relevance of a Socioeconomic Law,” Sociological Forum, Vol. 20, No. 2, 2005, pp. 209-244. doi:10.1007/s11206-005-4098-y

[7] G. Firebaugh, "The Trend in Between-Nation Income Inequality,” Annual Review of Sociology, Vol. 26, No. 1, 2000, pp. 323-339. doi:10.1146/annurev.soc.26.1.323

[8] B. Milanovic, "The Haves and the Have-Nots, a Brief and Idiosyncratic History of Global Inequality,” Basic Books, 
New York, 2011.

[9] J. E. Riggs, J. C. Hobbs, G. R. Hobbs and T. H. Riggs, “The Global Kuznets Curve, 1969-2007," Modern Economy, Vol. 3, No. 2, 2012, pp. 160-163.

doi:10.4236/me.2012.32022

[10] G. Firebaugh, "The New Geography of Global Income Inequality,” Harvard University Press, Cambridge, 2003.
[11] D. Acemolu and J. A. Robinson, "Why Nations Fail, the Origins of Power, Prosperity, and Poverty," Crown Business, New York, 2012.

[12] D. Acemoglu and J. A. Robinson, "The Political Economy of the Kuznets Curve," Review of Development Economics, Vol. 6, No. 2, 2002, pp. 183-203. $\underline{\text { doi: } 10.1111 / 1467-9361.00149}$ 